\title{
Middle Cuneiform Bone of the Foot
}

National Cancer Institute

\section{Source}

National Cancer Institute. Middle Cuneiform Bone of the Foot. NCI Thesaurus. Code C33116.

The second wedge-shaped bone between the internal and external cuneiforms bones in the distal row of the tarsus. 